\title{
Hydrothermal Synthesis of Hierarchical Nickel- or Cobalt- Based Carbonate Hydroxides for Supercapacitor Electrodes
}

\author{
Yaling Li, Pengcheng Li, Zhiqing Xin, Zhicheng Sun, Meijuan Cao and Luhai Li ${ }^{*}$ \\ Beijing Engineering Research Center of Printed Electronics, Beijing Institute of Graphic \\ Communication, Beijing 102600, PR China \\ *E-mail: liluhai@bigc.edu.cn
}

doi: $10.20964 / 2017.05 .50$

Received: 14 February 2017 / Accepted: 21 March 2017 / Published: 12 April 2017

\begin{abstract}
Nickel-, cobalt- and nickel-cobalt carbonate hydroxides were prepared with hydrothermal method and the crystal structure, thermal property and morphology were characterized. The electrochemical performance was also studied using the three-electrode method in $6 \mathrm{M} \mathrm{KOH}$ electrolyte. Nickel carbonate hydroxide and nickel-cobalt carbonate hydroxide have fluffy and hierarchical structures and exhibit much higher specific capacity compared to the as-prepared cobalt carbonate hydroxide. The specific capacity of nickel carbonate hydroxide achieves up to $169.6 \mathrm{~mA} \mathrm{~h} \mathrm{~g}^{-1}$ and that of the nickelcobalt carbonate hydroxide reveals $127.4 \mathrm{~mA} \mathrm{~h} \mathrm{~g}^{-1}$ at a current density of $1 \mathrm{~A} \mathrm{~g}^{-1}$. The two kinds of carbonate hydroxides exhibit superior cycling stability and have great application prospect for supercapacitor electrodes.
\end{abstract}

Keywords: carbonate hydroxide; hydrothermal method; superpacacitors; electrochemistry;

\section{FULL TEXT}

(C) 2017 The Authors. Published by ESG (www.electrochemsci.org). This article is an open access article distributed under the terms and conditions of the Creative Commons Attribution license (http://creativecommons.org/licenses/by/4.0/). 